\title{
Disparities in eating disorder diagnosis and treatment according to weight status, race/ethnicity, socioeconomic background, and sex among college students
}

\author{
K. R. Sonneville ScD, RD ${ }^{1}$
}

${ }^{1}$ Department of Nutritional Sciences, University of Michigan School of Public Health, Ann Arbor, Michigan

${ }^{2}$ Department of Health Management and Policy, University of Michigan School of Public Health, Ann Arbor, Michigan

\section{Correspondence}

Kendrin Sonneville, Assistant Professor, University of Michigan, School of Public Health, Ann Arbor, MI.

Email: kendrins@umich.edu

\author{
S. K. Lipson $\mathrm{PhD}^{2}$
}

\section{1 | INTRODUCTION}

Eating disorders present a significant threat to the health of adolescents and young adults in the United States (Chamay-Weber, Narring, \& Michaud, 2005; Rosen, 2010; Swanson, Crow, Le Grange, Swendsen, \& Merikangas, 2011). Eating disorders are associated with substantial psychiatric comorbidities (Chamay-Weber et al., 2005), and, because no organ system is spared the effects of eating disorders, the medical complications can be serious and even life- threatening (Rosen, 2010). Although approximately $5 \%$ of individuals in the United States will have an eating disorder at some point in their lives (Hudson, Hiripi, Pope Jr, \& Kessler, 2007) and many more will struggle with sub-threshold symptoms (Field et al., 2012, 2014; Haines, Hannan, van den Berg, Eisenberg, \& Neumark-Sztainer, 2013), eating disorders remain under-diagnosed and under-treated (Hart, Granillo, Jorm, \& Paxton, 2011). Only one-third of individuals with an eating disorder ever receive treatment (Hart et al., 2011), and disparities in treatment according to type of eating disorder are well 
described (Forrest, Smith, \& Swanson, 2017; Hudson et al., 2007; Keel et al., 2002; Swanson et al., 2011).

Failure to receive treatment for an eating disorder is likely due to a combination of factors including: a lack of perceived need for treatment among individuals with eating disorders (e.g., racial/ethnic minorities, those with obesity); failure on the part of clinicians to make a diagnosis/referral; and lack of treatment resources for some individuals with eating disorders (e.g., males, those with binge eating disorder [BED] or sub-threshold conditions). Antiquated ideas about who develops eating disorders, held by the general public and clinicians alike, may also perpetuate inequities in treatment. Specifically, eating disorders have historically been thought to afflict skinny, white, affluent girls, (Bruch, 1973) a generalization referred to in the popular press with the acronym SWAG. While countless epidemiologic studies show great diversity among individuals with eating disorder symptoms in terms of weight, race/ethnicity, socioeconomic background, and sex (Hudson et al., 2007; Lipson \& Sonneville, 2017; Swanson et al., 2011), the SWAG myth persists. Accordingly, higher-weight individuals, racial/ethnic minorities, those from socioeconomically disadvantaged backgrounds, and males may not recognize their need for treatment, may not be properly screened for eating disorders, and/or may never be referred to treatment. Research conducted in clinical samples may further perpetuate myths and stereotypes because of systematic differences between people who do and do not seek treatment (Gard \& Freeman, 1996; Hart et al., 2011; Mulders-Jones, Mitchison, Girosi, \& Hay, 2017).

While some studies have documented treatment disparities according to eating disorder diagnosis (Forrest et al., 2017; Hudson et al., 2007; Keel et al., 2002; Swanson et al., 2011), threshold anorexia nervosa (AN) and bulimia nervosa (BN) are the eating disorder presentations most likely to be included in existing studies, and few studies (Mond et al., 2009) include the full range of diagnoses in the Diagnostic and Statistical Manual of Mental Disorders, 5th Edition (DSM-5) (American Psychiatric Association, 2013). Further, disparities in perceived need for treatment, diagnosis, and treatment may warrant unique public health action; yet no studies have examined how individual factors (e.g., weight status, race/ethnicity, socioeconomic background, and sex) are associated with these related, but distinct, constructs.

Accordingly, in a large, diverse sample of undergraduate and graduate students in the United States with symptoms of an eating disorder, we examined variations in prevalence of perceived need for eating disorder treatment, eating disorder diagnosis, past-year eating disorder treatment, and barriers to receiving treatment according to weight status, race/ethnicity, socioeconomic background, and sex.

\section{2 | METHOD}

\section{1 | Data}

The healthy bodies study (HBS) is a population-level, web-based survey. We use aggregated HBS data from two academic years (20132014 and 2014-2015) with survey results from students at 12 colleges and universities across the country. HBS is administered to a randomly
WILEY EATING DISORDERS

selected sample of undergraduate and graduate students at participating institutions. Each participating school provides the HBS team with a random sample of up to 4,000 currently enrolled students who are at least 18 years of age. Students are then invited and reminded to participate in the survey via emails. HBS was administered using Qualtrics survey software and took students approximately $15 \mathrm{~min}$ to complete.

HBS response rates were 19\% in 2013-2014 and 27\% in 20142015. Although students are randomly selected from a list of all currently enrolled students, those who respond may not be fully representative of the population from which they are drawn. As such, we constructed sample probability weights to adjust for potential differences between responders and nonresponders, as has been done previously (Lipson \& Sonneville, 2017). Research was approved by the Institutional Review Boards at participating institutions. To further protect respondent privacy, the study was covered by a Certificate of Confidentiality from the National Institutes of Health.

\section{$2.2 \mid$ Measures}

In the HBS survey, participants provide extensive demographic information including age, sex, sexual orientation, race/ethnicity, and socioeconomic background. Participants also provide self-reported height and weight. Eating disorder symptoms are assessed using the validated and widely-used eating disorder examination questionnaire (EDE-Q) (Berg, Peterson, Frazier, \& Crow, 2012; Fairburn \& Cooper, 1993).

Perceived need for eating disorder treatment was assessed using the following question: Over the last 12 months, do you think you needed help such as counseling or therapy for issues related to eating and/or body image?, with "strongly agree" and "agree" coded as perceived need, and "neither agree nor disagree," "disagree," and "strongly disagree" coded as a lack of perceived need. HBS participants are asked about lifetime eating disorder diagnosis using a single question (Have you ever been diagnosed with any of the following psychological conditions?), with response options including eating disorder such as anorexia nervosa, bulimia nervosa, binge eating disorder. Participants are also asked about past-year eating disorder treatment (Over the last 12 months, have you received counseling or therapy for issues related to eating and/or body image from a health professional [such as a psychiatrist, psychologist, therapist, social worker, nutritionist, or primary care doctor]?).

Students who had not received eating disorder treatment in the past year and had a global EDE-Q score $\geq 2$ were asked about barriers to eating disorder treatment (Which of the following reasons are most important in explaining why you have not received counseling or therapy for your eating and/or body image concerns?). Students were able to select up to three reasons from a list of 21 options, including: Issues related to eating and body image are normal in college/graduate school; I'm not sure how serious my needs are; I don't have time; I prefer to deal with issues on my own; there are financial reasons (too expensive, insurance won't cover what I need); I worry that someone will notify my parents (or that they will see my visit on their insurance); and I have not had a need for counseling or therapy.

Weight status, race/ethnicity, socioeconomic background, and sex were operationalized to closely resemble characteristics represented by 
TABLE 1 Eating disorder symptom presentation

\begin{tabular}{|c|c|}
\hline & Criteria \\
\hline Threshold AN (N=13) & $\begin{array}{l}\text { 1. } \mathrm{BMI}<18.5 \\
\text { 2. } \mathrm{EDE}-\mathrm{Q} \geq 4\end{array}$ \\
\hline Threshold BN $(N=443)$ & $\begin{array}{l}\text { 1. No threshold AN } \\
\text { 2. } \geq 4 \text { Binging past month } \\
\text { 3. } \geq 4 \text { Purging past month } \\
\text { 4. EDE-Q } \geq 2\end{array}$ \\
\hline Threshold BED $(N=481)$ & $\begin{array}{l}\text { 1. No threshold } \mathrm{AN} \text { or threshold } \mathrm{BN} \\
\text { 2. } \geq 4 \text { Binging past month } \\
\text { 3. } \mathrm{EDE}-\mathrm{Q} \geq 2\end{array}$ \\
\hline $\begin{array}{l}\text { Sub-threshold BN } \\
(N=272)\end{array}$ & $\begin{array}{l}\text { 1. No threshold } A N \text {, threshold } B N \text {, } \\
\text { or threshold } B E D \\
\text { 2. } \geq 1 \text { Binging past month } \\
\text { 3. } \geq 1 \text { Purging past month } \\
\text { 4. EDE-Q } \geq 2\end{array}$ \\
\hline $\begin{array}{l}\text { Sub-threshold BED } \\
\qquad(N=197)\end{array}$ & $\begin{array}{l}\text { 1. No threshold } A N \text {, threshold } B N \text {, } \\
\text { threshold } B E D \text {, or sub-threshold } B N \\
\text { 2. } \geq 1 \text { Binging past month } \\
\text { 3. EDE-Q } \geq 2\end{array}$ \\
\hline $\mathrm{PD}(\mathrm{N}=341)$ & $\begin{array}{l}\text { 1. No threshold } A N \text {, threshold } B N \text {, } \\
\text { threshold } B E D \text {, sub-threshold } B N \text {, } \\
\text { or sub-threshold } B E D \\
\text { 2. } \geq 4 \text { Purging past month } \\
\text { 3. EDE-Q } \geq 2\end{array}$ \\
\hline
\end{tabular}

Note. $\mathrm{BMI}=$ body mass index (calculated from self-reported height and weight); $\mathrm{AN}=$ anorexia nervosa; $\mathrm{BN}=$ bulimia nervosa; $\mathrm{BED}=$ binge eating disorder; $\mathrm{PD}=$ purging disorder.

the SWAG myth and the presentation of results are organized accordingly. Specifically, we compared individuals with a body mass index (BMI) in the underweight range $(<18.5)$ to those with a BMI in the healthy weight (18.5-24.9, reference), overweight (25.0-29.9), and obese $(\geq 30.0$ ) categories. We collapsed self-reported race/ethnicity into two categories: white students and students of color (those who identified as Latino/a, African American, Asian, or other race/ethnicity, reference). To determine participants who would be considered affluent, socioeconomic background was assessed using the question: Which of the following best describes your socioeconomic background? (In other words, how would you describe your family's financial situation growing up?), with the following response options: well to do, comfortable, enough to get by but not many 'extras', and very poor, not enough to get by. Students were classified as either affluent (well to do) or nonaffluent (comfortable, enough to get by but not many 'extras', very poor, not enough to get by, reference). Individuals who identified as anything other than female or male (reference) were excluded from the analysis.

\section{3 | Analysis}

We classified individuals as having symptoms of an eating disorder based on DSM-5 criteria (American Psychiatric Association, 2013). As outlined in Table 1, our classification was based on BMI (calculated from self-reported height and weight), EDE-Q responses, and frequency of binging and purging behavior in the past month. Specifically, $\mathrm{BMI}<18.5$ and an EDE-Q global score $\geq 4$ (Luce, Crowther, \& Pole,
2008; Mond, Hay, Rodgers, \& Owen, 2006) was used to define threshold AN. An EDE-Q global score $\geq 2$ and responses to EDE-Q items about binging and purging were used to define threshold $\mathrm{BN}$, threshold $B E D$, sub-threshold $B N$, sub-threshold $B E D$, and purging disorder (PD). As in the DSM-5, we instituted a diagnostic hierarchy reflected in the order of Table 1, such that individuals could only meet criteria for one eating disorder. Of the 7,704 students who participated in HBS, 5,957 students who did not meet criteria for threshold AN, threshold BN, threshold BED, sub-threshold BN, sub-threshold BED, and PD were excluded from the analytic sample, leaving a final sample of 1,747.

Using bivariate analyses, we estimated the prevalence of perceived need for eating disorder treatment, any eating disorder diagnosis, and past-year eating disorder treatment, overall and by symptom presentation. In multivariable logistic regression models adjusting for age and sexual orientation, known correlates of eating disorder behaviors (Austin, Nelson, Birkett, Calzo, \& Everett, 2013; Lipson \& Sonneville, 2017), we estimated the odds of perceived need for eating disorder treatment, diagnosis, and past-year treatment according to weight status, race/ ethnicity, socioeconomic background, and sex. We report odds ratios (OR) and $95 \%$ confidence intervals $(\mathrm{Cl})$. We also examine treatment barriers by individual characteristics, weight status, and symptom presentation, reporting the top three barriers for each subgroup. All analyses were conducted using Stata 14.

\section{3 | RESULTS}

\section{1 | Sample characteristics}

In our analytic sample of students with symptoms of an eating disorder ( $N=1,747), 2.0 \%$ were underweight, $79.9 \%$ were White, $19.1 \%$ were affluent, and $84.9 \%$ were female. The most common eating disorder symptom presentations in our sample were threshold BED (26.8\%) and threshold BN (26.5\%; Table 2).

\subsection{Perceived need for treatment, diagnosis, and treatment by eating disorder symptom presentation}

In the overall sample, just $30.7 \%$ perceived a need for treatment, $10.5 \%$ had received a diagnosis, and $13.6 \%$ had received treatment in the past year. Individuals with threshold AN had the highest rates of perceived need for treatment (73.5\%), diagnosis (73.2\%), and past-year treatment (57.2\%; Table 3).

\section{3 | Multivariable correlates of perceived need for treatment, diagnosis, and past-year treatment}

Controlling for age and sexual orientation and compared to individuals with a healthy weight status (Table 4), those who were underweight were far more likely to perceive a need for treatment $(\mathrm{OR}=3.73,95 \%$ $\mathrm{Cl}=1.63$, 8.54), to have been diagnosed $(\mathrm{OR}=6.48,95 \% \mathrm{Cl}=3.14$, 13.37), and to have received treatment $(\mathrm{OR}=5.63,95 \% \mathrm{Cl}=2.74$, 11.55). Individuals with overweight $(\mathrm{OR}=.61,95 \% \mathrm{Cl}=.40, .95)$ and obesity $(\mathrm{OR}=.45,95 \% \mathrm{Cl}=.26, .78)$ were significantly less likely to have been diagnosed than individuals with a healthy weight. Compared 
TABLE 2 Sample characteristics (\%)

\begin{tabular}{|c|c|c|c|}
\hline & Overall $(N=1,747)$ & Female $(N=1,483)$ & Male $(N=264)$ \\
\hline \multicolumn{4}{|l|}{ Age } \\
\hline $18-20$ & 36.0 & 39.3 & 26.8 \\
\hline $21-23$ & 33.3 & 33.0 & 34.1 \\
\hline $24-27$ & 15.3 & 14.1 & 18.6 \\
\hline$\geq 28$ & 15.4 & 13.6 & 20.6 \\
\hline \multicolumn{4}{|l|}{ Sexual orientation } \\
\hline Sexual minority & 13.8 & 12.3 & 18.0 \\
\hline Heterosexual & 86.2 & 87.7 & 82.0 \\
\hline \multicolumn{4}{|l|}{ Race/ethnicity } \\
\hline White & 79.9 & 82.9 & 71.2 \\
\hline Student of color & 20.1 & 17.1 & 28.8 \\
\hline \multicolumn{4}{|c|}{ Socioeconomic background } \\
\hline Affluent & 19.1 & 20.5 & 15.2 \\
\hline Non-affluent & 80.9 & 79.5 & 84.8 \\
\hline \multicolumn{4}{|l|}{ Weight } \\
\hline UW & 2.00 & 2.3 & 1.1 \\
\hline HW & 50.2 & 56.2 & 32.8 \\
\hline OW & 28.6 & 26.1 & 35.6 \\
\hline OB & 19.3 & 15.4 & 30.4 \\
\hline \multicolumn{4}{|c|}{ Eating disorder symptom presentation } \\
\hline Threshold AN & .7 & .9 & 0 \\
\hline Threshold BN & 26.5 & 25.0 & 30.7 \\
\hline Threshold BED & 26.8 & 27.7 & 24.3 \\
\hline Sub-threshold BN & 15.7 & 15.3 & 16.8 \\
\hline Sub-threshold BED & 10.5 & 11.6 & 7.3 \\
\hline $\mathrm{PD}$ & 19.9 & 19.6 & 20.9 \\
\hline
\end{tabular}

Note. Table values are percentages of the weighted sample that met one of the six eating disorder symptom presentations described in Table 1. Weight categories are underweight ('UW') BMI (body mass index) <18.5; healthy weight ('HW') BMI = 18.5-24.9; overweight ('OW') BMI = 25.0-29.9; obese ('OB') $\mathrm{BMI} \geq 30.0$.

with students of color, white students were more likely to have been diagnosed $(\mathrm{OR}=1.81,95 \% \mathrm{Cl}=1.03,3.21)$. Socioeconomic background was associated with perceived need for treatment and pastyear treatment, with students from affluent backgrounds having higher odds of perceiving need $(\mathrm{OR}=1.52,95 \% \mathrm{Cl}=1.13,2.04)$ and of receiving treatment $(\mathrm{OR}=1.89,95 \% \mathrm{Cl}=1.31,2.72)$ compared with their non-affluent peers. Finally, females were more likely than males to perceive a need for treatment $(\mathrm{OR}=1.97,95 \% \mathrm{Cl}=1.35,2.86)$, to

TABLE 3 Perceived need, diagnosis, and treatment by eating disorder symptom presentation (\%)

\begin{tabular}{|llll|}
\hline & $\begin{array}{l}\text { Perceived need } \\
\text { for ED treatment }\end{array}$ & $\begin{array}{l}\text { Any ED } \\
\text { diagnosis }\end{array}$ & $\begin{array}{l}\text { Past year } \\
\text { ED treatment }\end{array}$ \\
\hline Overall & 30.7 & 10.5 & 13.6 \\
\hline Threshold AN & 73.5 & 73.2 & 57.2 \\
\hline Threshold BN & 41.5 & 15.1 & 19.3 \\
\hline Threshold BED & 32.2 & 6.6 & 13.2 \\
\hline Sub-threshold BN & 28.9 & 10.8 & 11.8 \\
\hline Sub-threshold BED & 21.5 & 5.7 & 9.0 \\
\hline PD & 19.6 & 9.9 & 8.8 \\
\hline
\end{tabular}

Note. Table values are percentages of the weighted sample. be diagnosed $(\mathrm{OR}=4.66,95 \% \mathrm{Cl}=1.80,12.11)$, and to be treated $(\mathrm{OR}=1.64,95 \% \mathrm{Cl}=1.00,2.67)$.

\section{4 | Barriers to treatment}

In the overall sample, the most commonly reported reasons for not seeking treatment were: "I prefer to deal with issues on my own" (28.1\%), "I have not had a need for counseling or therapy" (23.0\%), and "I'm not sure how serious my needs are" (19.7\%). Reported barriers to help-seeking were generally consistent across individual characteristics, weight status, and eating disorder presentation (Table 5).

\section{4 | DISCUSSION}

In a large and diverse sample of undergraduate and graduate students with eating disorder symptoms, we found that individual characteristics such as weight status, race/ethnicity, socioeconomic background, and sex-those associated with the SWAG stereotype-were highly associated with perceived need, diagnosis, and past-year treatment. Specifically, we found weight status and sex to be associated with perceived need for treatment, diagnosis, and past-year treatment. Race/ethnicity was associated with diagnosis, with greater odds of diagnosis among individuals who were white, and socioeconomic background was 
TABLE 4 Multivariable correlates of perceived need for treatment, diagnosis, and past-year treatment

\begin{tabular}{|c|c|c|c|}
\hline & $\begin{array}{l}\text { Perceived need for } \\
\text { ED treatment }\end{array}$ & Any ED diagnosis & $\begin{array}{l}\text { Past-year } \\
\text { ED treatment }\end{array}$ \\
\hline \multicolumn{4}{|l|}{ Sex } \\
\hline Female & $1.97(1.35,2.86)^{* * *}$ & $4.66(1.80,12.11)^{* *}$ & $1.64(1.00,2.70)^{*}$ \\
\hline Male [reference] & 1.00 & 1.00 & 1.00 \\
\hline \multicolumn{4}{|l|}{ Age } \\
\hline $18-20$ & $.86(.66,1.12)$ & $.61(.42, .88)^{* *}$ & $.62(.45, .86)^{* *}$ \\
\hline$\geq 21$ [reference] & 1.00 & 1.00 & 1.00 \\
\hline \multicolumn{4}{|l|}{ Sexuality } \\
\hline Sexual minority & $1.74(1.19,2.52)^{* *}$ & $1.31(.76,2.27)$ & $.93(.58,1.51)$ \\
\hline Heterosexual [reference] & 1.00 & 1.00 & 1.00 \\
\hline \multicolumn{4}{|l|}{ Race/ethnicity } \\
\hline White & $.89(.63,1.25)$ & $1.81(1.03,3.21)^{*}$ & $1.55(.97,2.48)$ \\
\hline Student of color [reference] & 1.00 & 1.00 & 1.00 \\
\hline \multicolumn{4}{|l|}{ Socioeconomic background } \\
\hline Affluent & $1.52(1.13,2.04)^{* *}$ & $1.48(1.00,2.19)$ & $1.89(1.31,2.71)^{* *}$ \\
\hline Non-affluent [reference] & 1.00 & 1.00 & 1.00 \\
\hline \multicolumn{4}{|l|}{ Weight } \\
\hline UW & $3.73(1.63,8.54)^{* *}$ & $6.48(3.14,13.37)^{* * *}$ & $5.63(2.74,11.55)^{* * *}$ \\
\hline HW [reference] & 1.00 & 1.00 & 1.00 \\
\hline OW & $.80(.59,1.07)$ & $.61(.40, .95)^{*}$ & $.81(.54,1.22)$ \\
\hline OB & $1.22(.88,1.69)$ & $.45(.26, .78)^{* *}$ & $1.37(.89,2.10)$ \\
\hline
\end{tabular}

Note. Table values are odds ratios and 95\% confidence intervals from three separate logistic regressions: (1) perceived need for ED treatment; (2) any ED diagnosis; and (3) past-year ED treatment.

${ }^{*} p<.05 ;{ }^{* *} p<.01 ;{ }^{* * *} p<.001$.

associated with perceived need for treatment and past-year treatment, with greater perceived need and odds of treatment seen among affluent individuals.

It is well established that the majority of people with eating disorders do not receive treatment, with studies reporting that only $20 \%-$ $30 \%$ receive treatment for their eating disorder (Forrest et al., 2017; Hart et al., 2011). Fewer individuals in our sample (13.6\%) reported treatment in the past year; this lower estimate is likely due to our use of a one-year time horizon and our inclusion of sub-threshold presentations. Specifically, we included diagnoses in the DSM-5 category of other specified feeing and eating disorders (OSFED), such as subthreshold BN, sub-threshold BED, and PD which are not included in most studies conducted prior to the release of the DSM-5. In alignment with other studies that have reported higher treatment-seeking among individuals with AN (Forrest et al., 2017; Keel et al., 2002), we found that individuals with symptoms of threshold AN, the least common eating disorder, were significantly more likely to perceive a need for eating disorder treatment, be diagnosed, and receive treatment when compared with individuals with other types of eating disorder presentations.

We found that underweight individuals were most likely to perceive a need for treatment and to receive a diagnosis or treatment. We also observed a lower likelihood of eating disorder diagnosis among individuals with overweight and obesity. This finding is supported by a systematic review of eating disorder treatment-seeking that found while only a minority of individuals with eating disorders receive appropriate mental health care, many receive treatment for weight loss (Hart et al., 2011). While it appears that concerns about weight appear to overshadow eating disorder-related concerns, it is not known how much of this provider-driven and how much is driven by the patient. In a qualitative study of women with bulimic-type eating disorders, Evans et al. (2011) found that women tended to seek help for concerns regarding perceived overweight rather than for their eating disorder symptoms, although many women would have welcomed questions from professionals regarding eating behaviors.

Compared with white students in our study, students of color were significantly less likely to receive an eating disorder diagnosis and nonsignificantly less likely to get treatment. Similarly, Cachelin and Striegel-Moore (2006) found in a community sample of Mexican American and European American women that while both groups were equally likely to believe they had significant eating problems and to want help, Mexican American women were less likely to have sought treatment and, having sought help, were less likely to have been diagnosed or treated. Similarly, Becker, Franko, Speck, and Herzog (2003) found that ethnic minority participants in the National Eating Disorders Screening Program were significantly less likely than non-minority participants to have been asked by a doctor about eating disorder symptoms, and Latino and Native American participants were significantly less likely than white participants to receive a recommendation or referral for further evaluation or care. Another study by Cachelin, Rebeck, Veisel, and Striegel-Moore (2001) examined barriers to treatment among an ethnically diverse sample and found a large discrepancy between wanting help for an eating problem and seeking treatment, and identified several barriers to treatment seeking, including financial 

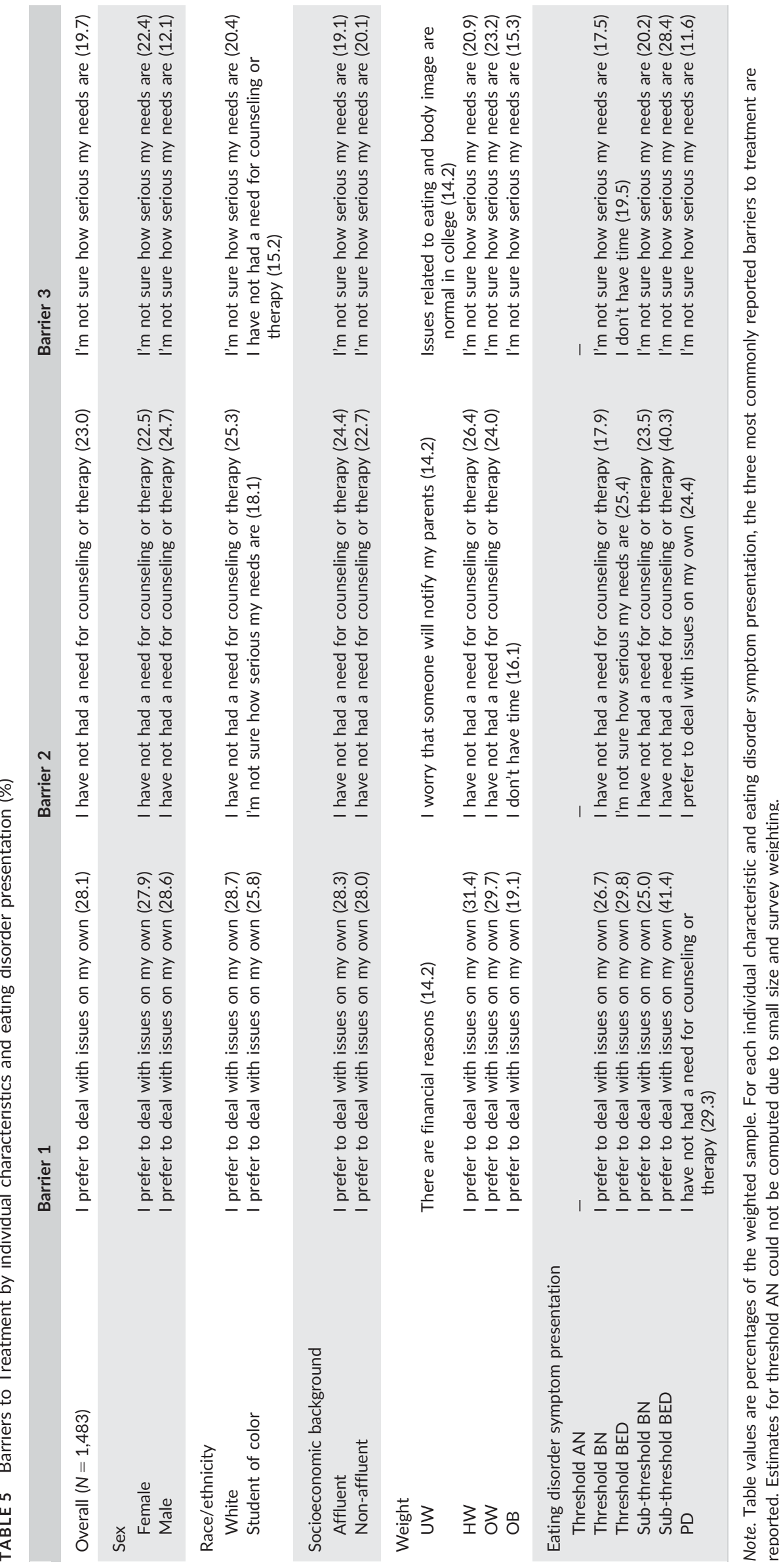
EATING DISORDERS WILEY difficulties and lack of insurance, not believing others could help, fear
of being labeled, not being aware of available resources, feelings of shame, and fear of discrimination. The type of barriers reported by Cachelin et al. were rarely endorsed in our study of college students; instead, the most commonly reported reasons related to a lack of perceived need and lack of urgency around need.

Eating disorder researchers often rely on clinical, rather than community samples, thereby perpetuating the myth that there is an increased prevalence of eating disorders in high-resourced groups who are more likely to access care (Gard \& Freeman, 1996). However, a recent population-based study conducted in Australia found that, in general, symptoms of eating disorders are distributed equally across levels of socioeconomic status (Mulders-Jones, Mitchison, Girosi, \& Hay, 2017). While socioeconomic background was not a predictor of eating disorder diagnosis in our study, we found that non-affluent students in our study were less likely to perceive a need for treatment and to receive treatment in the past year. These findings support the notion that specialist services for individuals with eating disorders may be less accessible to people from lower socioeconomic groups as specialist services are typically concentrated in more affluent areas and many of the services are offered within the private healthcare sector (MuldersJones et al., 2017).

Most studies of eating disorder-specific treatment-seeking among community samples do not include men (Hart et al., 2011), although Hudson et al. (2007) did report in a nationally-representative sample of U.S. adults lower lifetime treatment of BN and BED in males compared with females. In a study of individuals recruited from primary care sites in Australia, Hay, Loukas, and Philpott (2005) also found that males were less likely to seek treatment for their eating disorder symptoms than females. In a general population survey of adults in South Australia, Thapliyal et al. (2017) found that men with eating disorders were significantly less likely to receive treatment for a mental health problem or to be currently using an antidepressant when compared to women with eating disorders. In alignment with these findings, males in our sample were less likely to perceive a need and to receive eating disorder treatment or diagnosis. In general, eating disorders are especially under-diagnosed and under-treated in males, and because of gender differences in etiology and clinical presentation, may be misunderstood by many clinicians who encounter them (Strother, Lemberg, Stanford, \& Turberville, 2012; Weltzin et al., 2012).

Many individuals with eating disorders do not recognize themselves in stereotyped portrayals of eating disorders in the media and, for this and other reasons, they may also fail to recognize the need for treatment. Clinicians are also susceptible to these stereotypical beliefs, which may be further perpetuated by their exposure to treatmentseeking individuals and studies conducted among clinical samples. Because under-appreciation of the ubiquity of eating disorders by clinicians may influence screening practices, universal screening for eating disorders, rather than efforts that target underweight individuals or females, should be promoted to help minimize disparities in diagnosis. However, enhancing screening practices is only one step toward reducing treatment disparities. A range of factors related to health care delivery (e.g., treatment cost, availability, and/or acceptability of treatment) are relevant to receiving treatment. Specifically, treatment coverage and cost may influence the likelihood that individuals will be able to utilize available resource, as do issues related to shame and stigma (e.g., individuals of higher weights may feel uncomfortable or out of place in facilities that specialize in AN).

Our study has important implications for future research and practice related to eating disorder prevention and treatment in adolescent and young adult populations. Specifically, universal screening practices could be more fully adopted in clinical and community (e.g., colleges/ universities) settings, which typically conduct targeted screenings. In addition, future research should examine strategies to address inequities in diagnosis and treatment, including those designed to dispel myths, among the general public and clinicians alike, about the epidemiology of eating disorders. Moreover, the impact of interventions designed to increase diagnosis and referral in under-diagnosed and under-treatment populations on disease outcomes and prognosis should be evaluated.

\subsection{Strengths and limitations}

Response rate is a key limitation of our study, although we constructed non-response weights using administrative data on the full population to partially address this issue. Although we rely on the validated and widely-used EDE-Q to assess eating disorder symptoms (Berg et al., 2012; Fairburn \& Cooper, 1993), there is little consensus on how best to apply EDE-Q scores to diagnostic categories (Mond, Hay, Rodgers, Owen, \& Beumont, 2004); as such, the categories created using symptom presentation in this study should be considered proxies for the diagnostic categories. Some degree of diagnostic misclassification (e.g., false positives) would be expected for several reasons. First, the time horizon of the EDE-Q (past 28 days) is far shorter than the duration criteria for diagnosis (previous 3 months) and would be expected to result in inflated prevalence estimates. Second, we used an elevated EDE-Q global score as a marker of elevated eating disorder psychopathology, but this is not a specific indicator of the psychopathology needed for diagnosis. Furthermore, because the EDE-Q fails to capture the associated features of binge-eating episodes, the prevalence of clinically significant binge eating would likely be overestimated in our study (Binford, Le Grange, \& Jellar, 2005; Goldfein, Devlin, \& Kamenetz, 2005; Hay et al., 2017; Mitchison, Touyz, Gonzalez-Chica, Stocks, \& Hay, 2017), although not all studies find that the EDE-Q over identifies objective binge-eating episodes (Grilo, Masheb, \& Wilson, 2001a,b; Mond et al., 2004). Overall, false positives included in our sample would have resulted in exaggerated estimates of under-diagnosis and under-treatment. In addition, we used self-reported height and weight in our definition of $A N$; individuals with $A N$ who over-reported their weight may have been inaccurately classified as having another diagnosis. Finally, we created eating disorder categories using symptoms in the past four weeks, but our outcomes use longer time-horizons: perceived treatment need (past-year), eating disorder diagnosis (lifetime), and eating disorder treatment (past-year). Individuals who may have a history of an eating disorder, but did not report symptoms in the past four weeks were excluded from the analytic sample. Some bias would 
have been introduced if these individuals were systematically different from those in our study (e.g., more likely to have received treatment).

Despite these limitations, this study provides key information concerning disparities in eating disorder treatment among U.S. college students. The undergraduate years directly coincide with median age of onset for eating disorders (Hudson et al., 2007), and college and universities are well-positioned to increase eating disorder awareness and to lead prevention, detection, and early intervention efforts during an epidemiologically vulnerable and psychosocially significant time. Yet, many studies conducted among college students have limited generalizability because they are conducted at single sites and/or focus on defined subgroups (e.g., sorority women [Becker et al., 2010] or studentathletes [Becker, McDaniel, Bull, Powell, \& Mclntyre, 2012; Smith \& Petrie, 2008]). HBS is a population-level study conducted across multiple colleges and universities, thus findings may be more generalizable. Unlike other studies of treatment disparities, we examine the full range of diagnoses captured in the DSM-5 using symptoms assessed by the EDE-Q. Further, we were able to separately examine perceived need, diagnosis, and treatment, as well as barriers to treatment, providing greater insight into drivers of treatment inequities than prior studies. Our findings should be replicated in other college samples, and future studies should conduct a comprehensive examination of predictors of perceived need, diagnosis, and treatment across all types of eating disorders in non-college samples.

\section{5 | CONCLUSION}

Eating disorders are a source of significant morbidity and mortality in the United States. While early detection and treatment is associated with improved outcomes (Le Grange \& Loeb, 2007), under-diagnosis and under-treatment are common and represent threats to the health of adolescents and young adults. Disparities in perceived need, diagnosis, and treatment could lead to systemic differences in outcomes and may disadvantage people who already feel excluded from the prevailing discourse about eating disorders and marginalized within treatment settings.

\section{FINANCIAL DISCLOSURE}

The authors have no financial relationships relevant to this article to disclose.

\section{CONFLICT OF INTEREST}

The authors have no conflicts of interest to disclose.

\section{ORCID}

\section{K. R. Sonneville ScD, RD iD http://orcid.org/0000-0002-0359-3919}

\section{REFERENCES}

American Psychiatric Association (2013). Diagnostic and statistical manual of mental disorders: DSM-5 (9780890425596 0890425590 9780890425572 0890425574). Washington, DC. Retrieved from http://dsm.psychiatryonline.org/book.aspx?bookid $=556$
Austin, S., Nelson, L., Birkett, M., Calzo, J., \& Everett, B. (2013). Eating disorder symptoms and obesity at the intersections of gender, ethnicity, and sexual orientation in US high school students. American Journal of Public Health, 103(2), e16-e22.

Becker, A., Franko, D., Speck, A., \& Herzog, D. (2003). Ethnicity and differential access to care for eating disorder symptoms. International Journal of Eating Disorders, 33(2), 205-212. https://doi.org/10.1002/ eat.10129

Becker, C., McDaniel, L., Bull, S., Powell, M., \& Mclntyre, K. (2012). Can we reduce eating disorder risk factors in female college athletes? A randomized exploratory investigation of two peer-led interventions. Body Image, 9(1), 31-42. https://doi.org/10.1016/j.bodyim.2011.09.005

Becker, C., Wilson, C., Williams, A., Kelly, M., McDaniel, L., \& Elmquist, J. (2010). Peer-facilitated cognitive dissonance versus healthy weight eating disorders prevention: A randomized comparison. Body Image, 7 (4), 280-288. https://doi.org/10.1016/j.bodyim.2010.06.004

Berg, K., Peterson, C., Frazier, P., \& Crow, S. J. (2012). Psychometric evaluation of the eating disorder examination and eating disorder examination-questionnaire: A systematic review of the literature. International Journal of Eating Disorders, 45(3), 428-438. https://doi. org/10.1002/eat.20931

Binford, R. B., Le Grange, D., \& Jellar, C. C. (2005). Eating disorders examination versus eating disorders examination-questionnaire in adolescents with full and partial-syndrome bulimia nervosa and anorexia nervosa. International Journal of Eating Disorders, 37(1), 44-49. https://doi.org/10.1002/eat.20062

Bruch, H. (1973). Evolution of a psychotherapeutic approach to eating disorders: Obesity, anorexia nervosa, and the person within. New York, NY: Basic Books.

Cachelin, F. M., Rebeck, R., Veisel, C., \& Striegel-Moore, R. H. (2001) Barriers to treatment for eating disorders among ethnically diverse women. International Journal of Eating Disorders, 30(3), 269-278.

Cachelin, F. M., \& Striegel-Moore, R. H. (2006). Help seeking and barriers to treatment in a community sample of Mexican American and European American women with eating disorders. International Journal of Eating Disorders, 39(2), 154-161. https://doi.org/10.1002/eat.20213

Chamay-Weber, C., Narring, F., \& Michaud, P.-A. (2005). Partial eating disorders among adolescents: A review. Journal of Adolescent Health, 37(5), 416-426. https://doi.org/10.1016/j.jadohealth.2004.09.014

Evans, E. J., Hay, P. J., Mond, J., Paxton, S. J., Quirk, F., Rodgers, B., ... Sawoniewska, M. A. (2011). Barriers to help-seeking in young women with eating disorders: A qualitative exploration in a longitudinal community survey. Eating Disorders, 19(3), 270-285. https://doi.org/10. 1080/10640266.2011.566152

Fairburn, C., \& Cooper, Z. (1993). The eating disorder examination. In C. Fairburn \& G. Wilson (Eds.), Binge eating, nature, assessment and treatment (Vol. 12, pp. 317-360). New York, NY: Guilford Press.

Field, A. E., Sonneville, K. R., Crosby, R. D., Swanson, S. A., Eddy, K. T., Camargo, C. A., ... Micali, N. \&. (2014). Prospective associations of concerns about physique and the development of obesity, binge drinking, and drug use among adolescent boys and young adult men. JAMA Pediatrics, 168(1), 34-39. https://doi.org/10.1001/jamapediatrics.2013.2915

Field, A. E., Sonneville, K. R., Micali, N., Crosby, R. D., Swanson, S. A. Laird, N. M., ... Horton, N. J. (2012). Prospective association of common eating disorders and adverse outcomes. Pediatrics, 130(2), e289-e295. https://doi.org/10.1542/peds.2011-3663

Forrest, L. N., Smith, A. R., \& Swanson, S. A. (2017). Characteristics of seeking treatment among U.S. adolescents with eating disorders. International Journal of Eating Disorders, 50(7), 826-833. https://doi. org/10.1002/eat.22702 
Gard, M. C. E., \& Freeman, C. P. (1996). The dismantling of a myth: A review of eating disorders and socioeconomic status. International Journal of Eating Disorders, 20(1), 1-12. https://doi.org/10.1002/ (SICI)1098-108X(199607)20:1<1::AID-EAT1>3.0.CO;2-M

Goldfein, J. A., Devlin, M. J., \& Kamenetz, C. (2005). Eating disorder examination-questionnaire with and without instruction to assess binge eating in patients with binge eating disorder. International Journal of Eating Disorders, 37(2), 107-111. https://doi.org/10.1002/eat.20075

Grilo, C. M., Masheb, R. M., \& Wilson, G. T. (2001a). A comparison of different methods for assessing the features of eating disorders in patients with binge eating disorder. Journal of Consulting and Clinical Psychology, 69(2), 317-322.

Grilo, C. M., Masheb, R. M., \& Wilson, G. T. (2001b). Different methods for assessing the features of eating disorders in patients with binge eating disorder: A replication. Obesity Research, 9(7), 418-422. https://doi.org/10.1038/oby.2001.55

Haines, J., Hannan, P. J., van den Berg, P., Eisenberg, M. E., \& NeumarkSztainer, D. (2013). Weight-related teasing from adolescence to young adulthood: Longitudinal and secular trends between 1999 and 2010. Obesity, 21(9), E428-E434. https://doi.org/10.1002/oby.20092

Hart, L. M., Granillo, M. T., Jorm, A. F., \& Paxton, S. J. (2011). Unmet need for treatment in the eating disorders: A systematic review of eating disorder specific treatment seeking among community cases. Clinical Psychological Reviews, 31(5), 727-735. https://doi.org/10.1016/j.cpr.2011.03.004

Hay, P., Mitchison, D., Collado, A. E. L., González-Chica, D. A., Stocks, N., \& Touyz, S. (2017). Burden and health-related quality of life of eating disorders, including avoidant/restrictive food intake disorder (ARFID), in the Australian population. Journal of Eating Disorders, 5(1), 21. https://doi.org/10.1186/s40337-017-0149-z

Hay, P. J., Loukas, A., \& Philpott, H. (2005). Prevalence and characteristics of men with eating disorders in primary care: How do they compare to women and what features may aid in identification? Primary Care and Community Psychiatry, 10(1), 1-6.

Hudson, J. I., Hiripi, E., Pope, H. G. Jr., \& Kessler, R. C. (2007). The prevalence and correlates of eating disorders in the national comorbidity survey replication. Biological Psychiatry, 61(3), 348-358. https://doi. org/10.1016/j.biopsych.2006.03.040

Keel, P. K., Dorer, D. J., Eddy, K. T., Delinsky, S. S., Franko, D. L., Blais, M. A., . . Herzog, D. B. (2002). Predictors of treatment utilization among women with anorexia and bulimia nervosa. American Journal of Psychiatry, 159(1), 140-142. https://doi.org/10.1176/appi.ajp.159.1.140

Le Grange, D., \& Loeb, K. L. (2007). Early identification and treatment of eating disorders: Prodrome to syndrome. Early Intervention in Psychiatry, 1(1), 27-39. https://doi.org/10.1111/j.1751-7893.2007.00007.x

Lipson, S. K., \& Sonneville, K. R. (2017). Eating disorder symptoms among undergraduate and graduate students at 12 U.S. colleges and universities. Eating Behaviors, 24, 81-88. https://doi.org/10.1016/j.eatbeh. 2016.12.003

Luce, K. H., Crowther, J. H., \& Pole, M. (2008). Eating disorder examination questionnaire (EDE-Q): Norms for undergraduate women. International Journal of Eating Disorders, 41(3), 273-276. https://doi.org/ 10.1002/eat.20504

Mitchison, D., Touyz, S., Gonzalez-Chica, D. A., Stocks, N., \& Hay, P. (2017). How abnormal is binge eating? 18-Year time trends in population prevalence and burden. Acta Psychiatrica Scandinavica, 136(2), 147-155. https://doi.org/10.1111/acps.12735

Mond, J. M., Hay, P. J., Darby, A., Paxton, S. J., Quirk, F., Buttner, P., ... Rodgers, B. (2009). Women with bulimic eating disorders: When do they receive treatment for an eating problem? Journal of Consulting and Clinical Psychology, 77(5), 835-844. https://doi.org/10.1037/ a0015336

Mond, J. M., Hay, P. J., Rodgers, B., \& Owen, C. (2006). Eating disorder examination questionnaire (EDE-Q): Norms for young adult women. Behaviour Research and Therapy, 44(1), 53-62. doi:https://doi.org/10. 1016/j.brat.2004.12.003

Mond, J. M., Hay, P. J., Rodgers, B., Owen, C., \& Beumont, P. J. (2004). Validity of the eating disorder examination questionnaire (EDE-Q) in screening for eating disorders in community samples. Behaviour Research and Therapy, 42(5), 551-567. https://doi.org/10.1016/ s0005-7967(03)00161-x

Mulders-Jones, B., Mitchison, D., Girosi, F., \& Hay, P. (2017). Socioeconomic correlates of eating disorder symptoms in an Australian population-based sample. PLoS One, 12(1), e0170603. https://doi.org/10.1371/journal. pone.0170603

Rosen, D. (2010). Identification and management of eating disorders in children and adolescents. Pediatrics, 126(6), 1240-1253. https://doi. org/10.1542/peds.2010-2821

Smith, A., \& Petrie, T. (2008). Reducing the risk of disordered eating among female athletes: A test of alternative interventions. Journal of Applied Sport Psychology, 20(4), 392-407. https://doi.org/10.1080/ 10413200802241832

Strother, E., Lemberg, R., Stanford, S. C., \& Turberville, D. (2012). Eating disorders in men: Underdiagnosed, undertreated, and misunderstood. Eating Disorders, 20(5), 346-355. https://doi.org/10.1080/10640266. 2012.715512

Swanson, S. A., Crow, S. J., Le, G. D., Swendsen, J., \& Merikangas, K. R. (2011). Prevalence and correlates of eating disorders in adolescents: results from the national comorbidity survey replication adolescent supplement. Archives of General Psychiatry, 68(7), 714-723. https:// doi.org/10.1001/archgenpsychiatry.2011.22

Thapliyal, P., Mitchison, D., Miller, C., Bowden, J., Alejandro GonzálezChica, D., Stocks, N., ... Hay, P. (2017). Comparison of mental health treatment status and use of antidepressants in men and women with eating disorders. Eating Disorders, 1-15. https://doi.org/10.1080/ 10640266.2017.1383788

Weltzin, T. E., Cornella-Carlson, T., Fitzpatrick, M. E., Kennington, B., Bean, P., \& Jefferies, C. (2012). Treatment issues and outcomes for males with eating disorders. Eating Disorders, 20(5), 444-459. https://doi.org/10.1080/10640266.2012.715527

How to cite this article: Sonneville KR, Lipson SK. Disparities in eating disorder diagnosis and treatment according to weight status, race/ethnicity, socioeconomic background, and sex among college students. Int J Eat Disord. 2018;51:518-526. https://doi.org/10.1002/eat.22846 